\title{
Adolescent Male Chimpanzees at Ngogo, Kibale National Park, Uganda Have Decided Dominance Relationships
}

\author{
Hogan M. Sherrow \\ Hominid Behavior Research Project, Department of Sociology and Anthropology, Ohio \\ University, Athens, Ohio, USA
}

\author{
Key Words \\ Dominance $\cdot$ Chimpanzee $\cdot$ Adolescent
}

\begin{abstract}
Dominance relationships are common among primates, and are usually the result of resource competition. Adult male chimpanzees have pronounced dominance relationships, and can be ranked relative to one another in dominance hierarchies. Adult male chimpanzees achieve, and maintain, high rank through a combination of physical size, strength and political ability. Dominance in male chimpanzees has very real benefits as high-ranking males have priority access to resources and potential mates, and father more offspring than do low-ranking conspecifics. Previous research has suggested that adolescent male chimpanzees do not have dominance relationships with each other. Here, I report the first evidence of decided dominance relationships and a linear dominance hierarchy in adolescent male chimpanzees from an unusually large community of wild chimpanzees at Ngogo, Kibale National Park, Uganda.
\end{abstract}

Copyright $\odot 2012$ S. Karger AG, Basel

\section{Introduction}

Dominance relationships are common among primates and were one of the earliest behaviors recognized by primate ethologists. Dominant primates are those individuals with the ability to elicit subordinate behaviors from one or more conspecifics [Kummer, 1971] resulting in priority access to contested resources [Seyfarth, 1976]. It can be difficult to determine ranks between dyads, but researchers are typically able to identify high- and low-ranking individuals and are often able to identify alpha animals (e.g. Pan troglodytes [Goodall, 1986], Alouatta palliata [Wang and Milton, 2004]).

\begin{tabular}{ll}
\hline KARGER & ๑ 2012 S. Karger AG, Basel \\
Fax +41 61 306 12 34 & \\
$\begin{array}{l}\text { E-Mail karger@karger.ch } \\
\text { www.karger.com }\end{array}$ & $\begin{array}{l}\text { Accessible online at: } \\
\text { www.karger.com/fpr }\end{array}$
\end{tabular}

Hogan M. Sherrow

Department of Sociology and Anthropology

Ohio University, Bentley Annex 23

Athens, OH 45701 (USA)

E-Mail sherrow@ohio.edu 
Dominance relationships in male primates are typically the result of competition over resources, especially estrous females [Fedigan, 1983]. Competition over estrous females among adult male chimpanzees typically results in decided dominance relationships where subordinate group members consistently direct pant grunts to dominant conspecifics [de Waal, 1982; Goodall, 1986]. One of the striking elements of pant grunts is that subordinate individuals will often produce them in a preemptive manner, without provocation from the dominant individual [pers. observation]. In some instances, males can be ranked in a linear hierarchy, relative to one another [Goodall, 1986; Nishida and Hosaka, 1996; Boesch and Boesch-Achermann, 2000; Mitani et al., 2002; Muller and Wrangham, 2004]. Chimpanzee communities usually have a clear alpha male, and most males can be assigned to 'high', 'middle' and 'low' classes [Goodall, 1986; Newton-Fisher, 2004]. High-ranking males are more successful at acquiring copulations [Tutin, 1979; de Waal, 1982; Watts, 1998; Boesch and Boesch-Achermann, 2000; Watts, 2002] and have greater reproductive success than low-ranking males [Constable et al., 2001; Vigilant et al., 2001].

Three variables seem to be especially important for achieving and maintaining high rank among adult male chimpanzees: fighting ability, ability to form coalitions and alliances, and individual motivation [de Waal, 1982; Goodall, 1986; pers. observation]. As male chimpanzees mature, they gain muscle mass and confidence in their fighting abilities, resulting in their displaying to intimidate others, which in turn results in their acquiring a higher rank [de Waal, 1982; Pusey, 1990; Nishida and Hosaka, 1996]. Males can achieve an even higher rank if they are successful in forming coalitions with other males [de Waal, 1982; Nishida and Hosaka, 1996]. Individual drive to achieve high rank is not obviously quantifiable and is beyond the scope of this analysis.

Body size appears to influence adult male rank in many chimpanzee communities [de Waal, 1982; Goodall, 1986; Nishida and Hosaka, 1996; pers. observation] but to what extent is unclear [Pusey et al., 2005]. Males that are relatively large tend to be high ranking regardless of their ability to form coalitions or alliances [de Waal, 1982; Goodall, 1986; Nishida and Hosaka, 1996; pers. observation]. However, in an analysis of the long-term data from Gombe, Pusey et al. [2005] did not find a correlation between body size and dominance rank among males. Large males who become dominant have a difficult time maintaining rank and cannot typically hold on to the alpha position for an extended period of time without at least one ally [de Waal, 1982; Goodall, 1986; Nishida and Hosaka, 1996; Ngogo, unpubl. data]. Once again the exception to this pattern comes from Gombe, where Frodo was able to maintain his position as alpha for 6 years, despite not having a reliable ally [Pusey, pers. commun.]. Taken together, these results reconfirm that in chimpanzees much variation exists in status competition strategies. To what extent body size and political ability impact a male's ability to attain high rank is still not clear.

Chimpanzees have long periods of immaturity, even relative to most other nonhuman primate species [Goodall, 1986; Watts and Pusey, 1993; Fragaszy and Bard, 1997; Boesch and Boesch-Achermann, 2000; Pusey et al., 2005]. Male chimpanzee reproductive immaturity lasts at least 9 years [Leigh, 1996], and it typically takes 12 years or more before males begin gaining limited access to estrous females [Goodall, 1986; Pusey, 1990] and often 16 years or more before they successfully compete with other males, and can acquire high percentages of copulations. 
Upon reaching adolescence, males become independent of their mothers [Pusey, 1990] and make concerted efforts to associate with adult and other adolescent males [Goodall, 1986; Pusey, 1990]. During adolescence, male chimpanzees begin to integrate themselves into the adult male social network and to form social bonds with other males [Hayaki et al., 1989; Pusey, 1990]. They begin to assert themselves, first over females, and then over other males [Goodall, 1986; Pusey, 1990]. Adolescent males are typically subordinate to all adult males [Bygott, 1974; Goodall, 1986] but there is variation in their abilities to move up the male dominance hierarchy and to begin to dominate adult males [Goodall, 1971; Sherrow, in prep.].

Given that adult male chimpanzees in captivity and the wild have decided dominance relationships, it would not be surprising to find that adolescent males have similar social relationships, especially if higher-ranking males achieve greater access to a limited resource like food or estrous females. Despite attempts by adolescent males to compete over females, their success rates are typically low, and earlier studies have not found strong evidence for decided dominance relationships in adolescent male chimpanzees. In the only study that explicitly addressed this question, Hayaki et al. [1989] found that adolescent males at Mahale did not have decided dominance relationships with each other. Adolescent males rarely directed pant grunts to each other and there were numerous dyads in which neither male pantgrunted to the other [Hayaki et al., 1989].

Similar results have been reported for Gombe [Bygott, 1974; Goodall, 1986] and Tai [Boesch and Boesch-Achermann, 2000]. At Gombe, adolescent males were not considered part of the male hierarchy [Goodall, 1986]. Bygott [1974] found that larger, older immature (juvenile and adolescent) males were able to dominate smaller, younger immature males, but that signs of dominance typically occurred at the end of play sessions. In contrast to adult males, subordinate immature males did not use pant grunts as a way to recognize the rank of dominant males and preempt aggression. Further, pant grunts were inconsistent and rare among immature males [Bygott, 1974]. At Tai, males were reported to join the adult social hierarchy at the age of 15 [Boesch and Boesch-Achermann, 2004], a full 5-6 years after entering adolescence. Before that they were not reported as part of the adult male hierarchy, and no reference was made as to their ability to dominate one another [Boesch and BoeschAchermann, 2004].

Preliminary results [Sherrow, 2004] suggested that adolescent males at Ngogo have decided dominance relationships with each other that are like those of adult males, something that may distinguish them from age peers at other sites. Here, I present data on dominance relationships between adolescent male chimpanzees at Ngogo, Kibale National Park, Uganda, which confirms that adolescent males at Ngogo have decided dominance relationships with each other and that they can be ranked in a linear dominance hierarchy.

\section{Methods}

The Ngogo study area is in the center of the Kibale National Park in western Uganda. The study area is approximately $1,350 \mathrm{~m}$ above sea level and is comprised of primary and secondary rain forest. Rainfall averages about $1,600 \mathrm{~mm}$ /year and usually falls during two rainy seasons [Struhsaker, 1997]. The Ngogo chimpanzee community is the largest on record and during the study period had approximately 140-150 members, including 25 adult males, 17 
adolescent males and 40-50 adult females. In 1995, Watts and Mitani began a long-term study of the Ngogo chimpanzee community, and since that time the chimpanzees at Ngogo have been observed continuously.

I used focal, ad libitum and all-occurrence methods [Altmann, 1974] to record data on agonistic interactions between 14 adolescent males that were present and adolescent for at least 3 of my 4 different field seasons: May to August 2000, July to August 2002, July to December 2003 and July to December 2004. I complied with protocols approved by Yale University's animal care committee and adhered to the legal requirements of Uganda. I recorded data on agonistic interactions between these males in all contexts, including when an estrous female was in a party. Adolescent males had descended testicles, were fully independent of their mothers, but were still growing in mass and linear dimensions [Sherrow, 2008]. To determine if males were still growing, I used independent assessments by myself, Professors David Watts and John Mitani, and the four Ngogo Chimpanzee Project field assistants reported once a year on each of the young males in the community. I then combined the results of those assessments and used a best-fit model to determine if a particular male was still growing. Relative body size was estimated by independent comparisons by myself, the two PIs on the project and the four Ngogo field assistants of dyads of males when they were in proximity to one another. I then combined the results of those assessments and used a best-fit model to determine relative body sizes of adolescent males.

Agonistic behaviors included, but were not limited to, supplant, charge, chase and avoid, pant grunt and flee. While supplants, charging and chasing are very informative about dominance relationships within dyads, pant grunts are the most reliable indicators of dominance relationships among chimpanzees. Pant grunts are always directed from a subordinate to a dominant animal [de Waal, 1982; Goodall, 1986], and I used them in this study to determine dominance relationships. I recorded behaviors of my focal animals continuously while they could be observed and took 30-min scans of the entire party during which I recorded the identities of all individuals present and their general behaviors (e.g. resting, feeding).

I constructed a pant grunt matrix for all adolescent males and used MatMan 1.1 to calculate Kendall's coefficient of linearity (K), Landau's index and the index of linearity (h'). Each index varies from 0 (absence of linearity) to 1 (complete linearity). $h$ ' is based on $\mathrm{h}$ and takes into account the existence of unknown relationships. All analyses were based on 10,000 permutations and all tests were two-tailed.

\section{Results}

Adolescent males at Ngogo directed pant grunts to each other in a unidirectional (directional consistency index $=0.939)$ and linear $\left(h^{\prime}=0.56 ; \mathrm{K}=0.46 ; \mathrm{pr}=\right.$ 0.002; $\mathrm{pl}=0.998)$ manner. As a result, I placed the adolescent males in a linear dominance hierarchy using the refit for linear hierarchy function in MatMan 1.1 (table 1). I recorded 99 pant grunts between adolescent males. There were only 2 instances when members of one dyad pant-grunted to each other and the dominance relationship of that dyad appeared to be in flux. On multiple occasions GZ and WB failed to clearly dominate each other and instead exchanged pant grunts. This continued for two field seasons and the two males often avoided each other. However, by the end of my study WB consistently pant-grunted to GZ in a unidirectional manner.

Dominance ranks among adolescent males tended to correlate with age category. However, there were 2 cases in which smaller, and presumably younger, males (GZ and CA) were higher ranking than expected, based on their body size. Both males were higher ranking than several other males that were bigger, and presumably older, than they were. There were also 2 cases in which larger and presumably older 
Table 1. Adolescent male age categories and dominance ranks based on pant grunt matrices

\begin{tabular}{lll}
\hline Code & Age category & Dominance rank \\
\hline DX & late adolescent & 1 \\
GZ & late adolescent & 2 \\
RN & late adolescent & 3 \\
WB & late adolescent & 4 \\
TA & late adolescent & 5 \\
RO & late adolescent & 6 \\
BD & late adolescent & 7 \\
RI & late adolescent & 8 \\
CA & middle adolescent & 9 \\
MU & middle adolescent & 10 \\
GT & middle adolescent & 11 \\
WA & late adolescent & 12 \\
SA & early adolescent & 13 \\
JA & early adolescent & 14 \\
CS & early adolescent & 15 \\
SP & early adolescent & 16 \\
HH & early adolescent & 17 \\
\hline
\end{tabular}

males were lower ranking than expected, based on their body size (GT, WA). Both of these males were lower ranking than males that were smaller, and presumably younger, than they were.

\section{Discussion}

Adolescent male chimpanzees at Ngogo had decided dominance relationships and could be ranked relative to one another in a linear dominance hierarchy. While the stability and strength of the linear hierarchy was not particularly high $\left(h^{\prime}=0.56\right)$ that was probably due to unknown relationships between males. Despite the unknown aspect of some relationships, the adolescent males at Ngogo could still be ranked relative to one another in a linear hierarchy, indicating that this is a real effect. This result contrasted with the findings of Hayaki et al. [1989] regarding dominance relationships among adolescent males at Mahale. Hayaki and colleagues ranked the adolescent males relative to one another, but they recorded few pant grunts and stated that adolescent males at Mahale did not have regular dominance relationships.

There are several possible reasons for the differences in observed adolescent male dominance relationships at Mahale and Ngogo, including differences in study methodologies, differences in community demographics and differences in adolescent male social relationships. My methods differed slightly from those used by Hayaki et al. They collected data on pant grunts primarily through ad libitum techniques and their study was shorter than mine, which could have led to smaller sample sizes, re- 
sulting in few pant grunts observed. Despite these differences, the data do not support the idea that the methodological variation led to differences in results. Hayaki et al. [1989] observed 415 pant grunts between males and, even though they were focusing on adolescent males, most were given by adolescent and young adult males to prime adult males. I recorded 99 pant grunts between adolescent males during my study and while the adolescent males at Ngogo pant-grunted to adult males quite often they pant-grunted frequently and independently to each other.

Community size and demographic composition differed between Mahale and Ngogo. The difference in the number of males in the two communities could have impacted the number of pant grunts observed during the two studies. Ngogo is an unusually large community with approximately 150 members, including approximately 25 adult and 17 adolescent males. Mahale, on the other hand, had approximately 100 group members, with 10 adult and 9 adolescent males [Hayaki et al., 1989]. There were almost twice as many adolescent males in the Ngogo community as in the Mahale community during the study of Hayaki et al. [1989]. Further, reproductively viable males in the Mahale community made up approximately $1 / 6$ of the total community population, while at Ngogo that ratio was nearly $1 / 3$.

An alternative to the possibility of differences in methodology is that adolescent males at Ngogo had qualitatively different relationships with each other than adolescent males at Mahale did. Dominance relationships should form when the potential for contest competition is high, high rank provides individuals with priority of access or the ability to monopolize resources, and priority of access or monopolization leads to fitness advantages. The formation of dominance hierarchies among immature males in response to resource competition is not unprecedented among non-human (Macaca mulatta [Bernstein et al.,1993], Cercocebus spp. [Gust, 1995]) or human [Pellegrini and Bartini, 2001; Geary et al., 2003] primates or other mammals (e.g. Crocuta crocuta [Engh et al., 2005]).

In all chimpanzee communities, adolescent males compete with not only adult males, but also each other, for access to estrous females [Watts, 1998] and, potentially, other males [Watts, 2000]. In chimpanzee communities other than Ngogo, adolescent males compete with between 10 and 15 other males for access to estrous females. At Ngogo, each male must compete with between 35 and 40 others. While access to estrous females provides potential fitness payoffs through reproductive success [Vigilant et al., 2001], adolescent males are typically less successful at acquiring copulations than most adult males [Constable et al., 2001]. Despite their limited success, adolescent males continue to compete with each other, and adult males, over access to estrous females [pers. observation].

Access to male social partners may provide adolescent males with fitness payoffs through coalitionary support or the opportunity to use adult males as behavioral role models during development. Adolescent males at Ngogo do not regularly receive coalitionary support from adult or other adolescent males [Sherrow, 2008]. As a result, competition over coalition partners cannot be considered a selective force in the formation of dominance hierarchies. However, high rank may provide adolescent males with priority access to adult males who make good role models for behavioral development [Sherrow, in preparation].

The data presented here suggest that, like other immature primate males, adolescent male chimpanzees at Ngogo formed decided dominance relationships with each other in response to competition over resources. Adolescent males at Ngogo ap- 
pear to face intense competition for access to estrous females [Watts, 1998] and, potentially, access to other males [Sherrow, in preparation] resulting in those males developing dominance relationships as part of their competitive strategies.

Larger and presumably older adolescent males tended to be higher ranking than smaller and presumably younger adolescent males. However, there were 4 males who did not conform to the pattern observed in the other males. Two of those males (CA and GZ) were higher ranking than expected, dominating males that were larger, and presumably older, than they were. If these were adult males, it would not be particularly surprising that some smaller males were higher ranking than larger males. Adult males have extensive coalitions and alliances that strongly impact their ability to dominate others [de Waal, 1982; Nishida and Hosaka, 1996]. As a result, the highest-ranking males in a chimpanzee community are not always the largest or strongest [pers. observation]. For example, at Gombe Pusey et al. [2005] found no correlation among adult males between dominance rank and body size. However, as adolescent males do not regularly form coalitions with each other or adults and appear to largely acquire rank through individual power and fighting ability, the relatively high ranks of CA and GZ remain unexplained.

Two males were lower ranking than expected, acting submissively to males that were smaller, and presumably younger, than they were. Interestingly, both of those males were limited in their physical abilities due to snare injuries they suffered while young. GT had a rope snare on his left hand and was small for his presumed age. While he was eager to take part in competitions with other males, often joining in displays, GT was limited by his handicap and often retreated from smaller males when he was confronted. WA was missing his left hand and was apprehensive around other males. He would often take measures to avoid conflicts between males and rarely displayed. Snare injuries are not uncommon among the Ngogo chimpanzees, with approximately $25 \%$ of the adult community bearing the scars of snares [unpubl. data]. Injuries from snares and other factors have been shown to impact dominance in chimpanzees at Gombe [Goodall, 1986] and probably impacted the dominance ranks of GT and WA.

The results presented here indicate that adolescent male chimpanzees at Ngogo had decided dominance relationships and could be ranked in a linear hierarchy relative to one another. A linear hierarchy among adolescent males indicates that they competed with each other over access to resources. Future analyses will focus on competition between adolescent males over access to estrous females and adult males and the influence of adolescent male social effort and adult male rank on adolescent male dominance rank.

\section{Acknowledgements}

I thank the Uganda Wildlife Authority and Uganda National Council for Science and Technology for permission to conduct research in Kibale. I am grateful to Makerere University Biological Field Station and its Directors at the time, Professors Basuta and Kasenene, for their sponsorship and support. I thank Professors Mitani and Watts for the opportunity to work at Ngogo; they have been sources of continual support and guidance. I thank Dr. Jeremiah Lwanga, who is not only a good friend, but also a great advisor and companion while in the field. A. Magoba, G. Mbabazi, L. Ndagizi and A. Tumusiime provided invaluable assistance in the field. The L.S.B. Leakey Foundation, the American Society of Primatologists, the Sigma Xi Foundation, the John F. Enders Foundation and Yale University provided support. 


\section{References}

Altmann J (1974). Observational study of behavior: sampling methods. Behaviour 49: 227-265.

Bernstein IS, Judge PG, Ruehlmann TE (1993). Sex-differences in adolescent rhesus monkey (Macaca mulatta) behavior. American Journal of Primatology 31: 197-210.

Boesch C, Boesch-Achermann H (2000). The Chimpanzees of the Tai Forest: Behavioural Ecology and Evolution. Oxford, Oxford University Press.

Bygott JD (1974). Agonistic Behaviour in Wild Male Chimpanzees. PhD dissertation, University of Cambridge.

Constable JL, Ashley MV, Goodall J, Pusey AE (2001). Noninvasive paternity assignment in Gombe chimpanzees. Molecular Ecology 10: 1279-1300.

De Waal F (1982). Chimpanzee Politics: Power and Sex among Apes. Baltimore, Johns Hopkins University Press.

Engh AL, Siebert ER, Greenberg DA, Holekamp KE (2005). Patterns of alliance formation and postconflict aggression indicate spotted hyaenas recognize third-party relationships. Animal Behaviour 69: 209-217.

Fedigan LM (1983). Dominance and reproductive success in primates. Yearbook of Physical Anthropology 26: $85-123$.

Fragaszy DM, Bard K (1997). Comparison of development and life history in Pan and Cebus. International Journal of Primatology 18: 683-701.

-Geary DC, Byrd-Craven J, Hoard MK, Vigil J, Numtee C (2003). Evolution and development of boys' social behavior. Developmental Review 23: 444-470.

Goodall J (1986). The Chimpanzees of Gombe: Patterns of Behavior. Cambridge, Belknap Press.

Gust DA (1995). Moving up the dominance hierarchy in young sooty mangabeys. Animal Behaviour 50: $15-21$.

- Hayaki H, Huffman MA, Nishida T (1989). Dominance among male chimpanzees in the Mahale Mountains National Park, Tanzania - a preliminary study. Primates 30: 187-197.

Kummer H (1971). Primate Societies: Group Techniques of Ecological Adaptations. Chicago, Aldine Atherton.

Leigh SR (1996). Evolution of human growth spurts. American Journal of Physical Anthropology 101: 455-474.

Mitani JC, Watts D, Muller M (2002). Recent developments in the study of wild chimpanzee behavior. Evolutionary Anthropology 11:9-25.

Muller MN, Wrangham RW (2004). Dominance, cortisol and stress in wild chimpanzees (Pan troglodytes schweinfurthii). Behavioral Ecology and Sociobiology 55:332-340.

Newton-Fisher NE (2004). Hierarchy and social status in Budongo chimpanzees. Primates 45:81-87.

Nishida T, Hosaka K (1996). Coalition strategies among adult male chimpanzees of the Mahale Mountains, Tanzania. In Great Ape Societies (McGrew WC, Marchant LF, Nishida T, eds.), p 114-134. Cambridge, Cambridge University Press.

- Pellegrini AD, Bartini M (2001). Dominance in early adolescent boys: affiliative and aggressive dimensions and possible functions. Merrill-Palmer Quarterly 47: 142-163.

Pusey AE (1978). The Physical and Social Development of Wild Adolescent Chimpanzees (Pan troglodytes schweinfurthii). PhD dissertation, Stanford University.

- Pusey AE (1990). Behavioral changes at adolescence in chimpanzees. Behaviour 115: 203-246.

Pusey AE, Oehlert GW, Williams JM, Goodall J (2005). Influence of ecological and social factors on body mass of wild chimpanzees. International Journal of Primatology 26: 3-31.

- Seyfarth R (1976). Social relationships among adult female baboons. Animal Behaviour 24: 917-938.

- Sherrow HM (2004). Dominance relationships of adolescent male chimpanzees at Ngogo, Kibale National Park, Uganda. Folia Primatologica 75 (suppl. 1): 333.

Sherrow HM (2008). Variation in and Ontogeny of Social Behavior in Wild Young Male Chimpanzees at Ngogo, Kibale National Park, Uganda. PhD thesis, Yale University.

Sherrow HM (in preparation). The behavioral role modeling hypothesis and the ontogeny of behavior in wild male chimpanzees. American Journal of Physical Anthropology.

Struhsaker TT (1997). Ecology of an African Rain Forest: Logging in Kibale and the Conflict between Conservation and Exploitation. Gainesville, University Press of Florida.

Tutin CEG (1979). Mating patterns and reproductive strategies in a community of wild chimpanzees (Pan troglodytes schweinfurthii). Behavioral Ecology and Sociobiology 6: 29-38.

-Vigilant L, Hofreiter M, Siedel H, Boesch C (2001). Paternity and relatedness in wild chimpanzee communities. Proceedings of the National Academy of Sciences of the United States of America 98: 12890-12895.

Wang E, Milton K (2004). Intragroup social relationships of male Alouatta palliata on Barro Colorado Island, Republic of Panama. International Journal of Primatology 24: 1227-1244. 
Watts DP (1998). Coalitionary mate guarding by male chimpanzees at Ngogo, Kibale National Park, Uganda. Behavioral Ecology and Sociobiology 44: 43-55.

Watts DP (2000). Grooming between male chimpanzees at Ngogo, Kibale National Park. II. Influence of male rank and possible competition for partners. International Journal of Primatology 21: 211238.

Watts DP (2002). Reciprocity and interchange in the social relationships of wild male chimpanzees. Behaviour 139: 343-370.

Watts DP, Pusey A (1993). Behavior of juvenile and adolescent great apes. In Juvenile Primates: Life History, Development, and Behavior (Pereira ME, Fairbanks LA, eds.), pp 148-167. New York, Oxford University Press. 